Effects of el ectrical I esi ons of the nedi al preopt i c area and the vent ral pal I i dum on mat e- dependent paternal behavi or i $\mathrm{n}$ m ce

\begin{tabular}{|c|c|}
\hline 著者 & アクダール シリン \\
\hline 著者別表示 & Akt her Shi ri n \\
\hline $\begin{array}{l}\text { j our nal or } \\
\text { publ i cat i on } \mathrm{title}\end{array}$ & 博士論文本文Ful I \\
\hline 学位授与番号 & 13301甲第4096号 \\
\hline 学位名 & 博士 (医学) \\
\hline 学位授与年月日 & $2014-09-26$ \\
\hline URL & ht t p: //hdl . handl e. net /2297/41998 \\
\hline
\end{tabular}




\title{
Effects of electrical lesions of the medial preoptic area and the ventral pallidum on mate-dependent paternal behavior in mice
}

\author{
Shirin Akther, Azam A.K.M. Fakhrul, Haruhiro Higashida* \\ Department of Basic Research on Social Cognition, Kanazawa University Center for Child Mental Development, Kanazawa 920-8640, Japan
}

\section{H I G H L I G H T S}

- The mouse sires displayed mate-dependent paternal behavior.

- This parental behavior was disrupted by electrical brain lesions.

- The medial preoptic area and ventral pallidum are involved in the paternal behaviors.

\section{A R T I C L E I N F O}

\section{Article history:}

Received 10 January 2014

Received in revised form 25 March 2014

Accepted 29 March 2014

Available online 8 April 2014

\section{Keywords:}

Parental behavior

Paternal behavior

Retrieval

Medial preoptic area

Ventral pallidum

Electric brain lesion

\begin{abstract}
A B S T R A C T
In laboratory animals, less is known about the neural circuits that mediate paternal behavior than those that influence maternal behavior. In mice, we recently reported that when sires are separated with their mate dams from their pups, ultrasound and pheromonal signals from the dams can evoke and initiate maternal-like retrieval behavior in the sires upon reunion with the offspring; this is termed mate-dependent paternal care. We used electrolytic brain lesion (EBL) methods to identify the potential roles of the medial preoptic area (mPOA) and ventral pallidum (VP) regions in regulating paternal care, areas known to be critical for the expression of maternal behavior. Electrolytic lesions of the MPOA or VP disrupted mate-dependent paternal care; latencies to initiate pup retrieval, grooming and crouching were longer in the EBL-treated sires relative to the sham-operated mice. The number of grooming episodes and duration of crouching were also lower in sires with the EBL in both areas. These results indicate that the MPOA and VP regions are essential for mate-dependent paternal care in mice.
\end{abstract}

(C) 2014 Elsevier Ireland Ltd. All rights reserved.

\section{Introduction}

Most of our knowledge of mammalian parental behavior is based on studies of mother-infant interactions. There is evidence supporting the hypothesis that the mammalian father is an important participant and contributor to the care and development of offspring [1-4]. However, this behavior is dependent on the species, as most mammalian fathers exhibit notably little paternal care, and only a small portion exhibit full/obligatory paternal care [3,5-10]. Parental behavior of rodents is defined as behavior directed toward offspring that increases their survival (e.g., nurturing, nesting, and retrieving) [5,6]. The significance of such paternal care, particularly because not all species exhibit paternal care, has been an area of debate. This uncertainty could be partially resolved by examining the neuroanatomical and molecular substrates and

\footnotetext{
* Corresponding author at: 13-1 Takara-machi, Kanazawa 920-8640, Japan. Tel.: +81 76265 2455; fax: +81 762654213 .

E-mail address: haruhiro@med.kanazawa-u.ac.jp (H. Higashida).
}

neurocircuitry associated with such paternal behavior. Such studies could provide some significant findings to understand human male parental behavior and social interaction, which contribute to developmental psychiatric diseases, including autism and schizophrenia $[9,11,12]$, although there is a wide gap between animal models and humans.

There are several (widely used) laboratory mouse strains that exhibit varying levels of spontaneous paternal care - some are in fact quite paternal $[2,3,6,8,13]$. However, uniparental male mice that are forced to live together exhibit maternal-like behavior, including providing protection and warmth to offspring [13]. We recently developed a co-housing paradigm to study paternal behavior of the mouse ICR strain [14-16]. When mouse sires are continuously housed in the maternal cage with their mates and pups for three to five days prior to and after parturition, they exhibit signs of maternal-like parental care. Furthermore, when separated from their pups for $10 \mathrm{~min}$ and co-housed with the dam in a new cage, sires exhibited retrieval behavior when reunited with their pups [14]. We also found that expression of male parental behavior is triggered by olfactory and unique $38-\mathrm{kHz}$ ultrasonic 

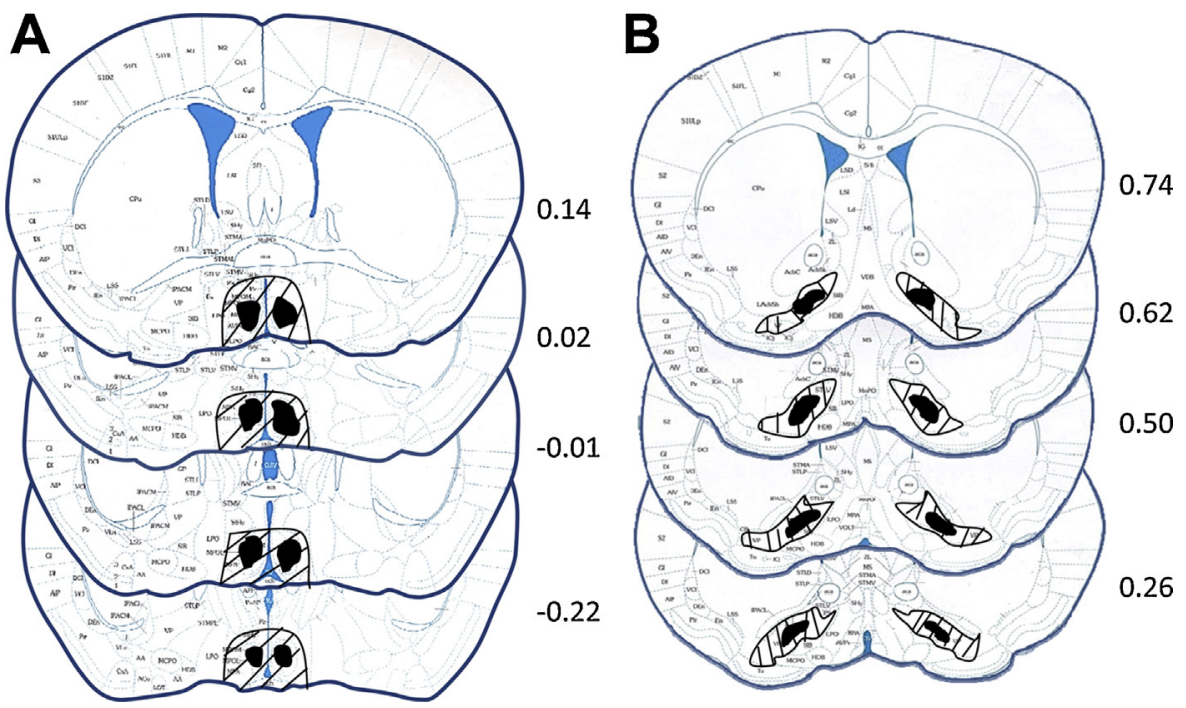

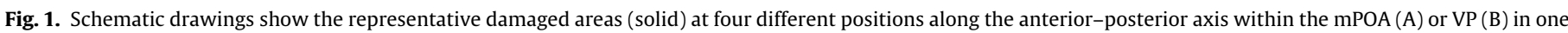

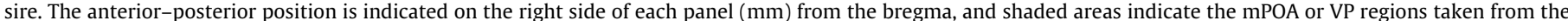
reference of Franklin and Paxinos (2009).

auditory signals to the sire from the mate dam. Thus, we defined this behavior displayed in the ICR male mice as mate-dependent paternal behavior induced by the interactive communication from the dam to the sire.

Although we have identified several conditions that elicit mate-dependent paternal behavior, little is known about the neurocircuitry responsible for this behavior. We recently reported that central cholinergic cellular signaling [15] and CD38 and oxytocin signaling in the nucleus accumbens (NACC) [16] are critical for the expression of paternal care. However, it is not yet known if the brain regions responsible for maternal behavior, the medial preoptic area (mPOA), the ventral tegmental area (VTA), the NAcc and the ventral pallidum (VP), also regulate paternal behavior $[5,6,17,18]$. To address this issue, we use a classical deletion method, the electrolytic brain lesion (EBL) technique, according to the details described by Lee and Brown [26], to determine the extent to which the $\mathrm{MPOA}$ and VP regions regulate paternal care in mice of the ICR strain [19], since we hypothesize that the brain lesions may affect paternity. We first focus on paternal behavior by lesioned sires mated with intact dams, because sires isolated alone do not display paternal behavior, dams inevitably care pups, and dams are needed for sires to induce paternal care [14]. Next, we test pup care behavior and pup survival in the sire plus dam lesion groups to confirm if they are behaviorally different from the sire-only-lesion groups. Finally, we use sires of non-treated or sham-operated sires as a control experiment.

\section{Methods}

\subsection{Animals}

Males and females of the Slc:ICR line were obtained from Japan SLC Inc. (Hamamatsu, Japan) and kept in our laboratory, as described previously $[14,19]$. Virgin males and females were paired on postnatal days 45-55. All experiments were approved by the Committee on Animal Experimentation of Kanazawa University.

\subsection{Electrical brain lesion procedure}

After seven days of mating, both mice of a given mating pair or only the male counterpart underwent bilateral EBL or sham lesions to the mPOA or VP regions. Mice were anesthetized with Somnotol
(65 mg/kg ip, diluted $1: 10$ in sterile saline) and covered with a cotton cloth to maintain normal body temperature in the surgery room at $25^{\circ} \mathrm{C}$. Mice were securely placed into a stereotaxic apparatus (Narushige Instrument Inc., Tokyo, Japan) with the skull level between bregma and lambda.

The stereotaxic coordinates were determined from a standard atlas of the mouse brain by Franklin and Paxinos [20] and were set as follows: $\mathrm{mPOA}=\mathrm{AP}+0.02 \mathrm{~mm}$, DV $5.5 \mathrm{~mm}, \mathrm{ML} \pm 0.3 \mathrm{~mm}$; $\mathrm{VP}=\mathrm{AP}+0.62 \mathrm{~mm}$, DV $5.0 \mathrm{~mm}, \mathrm{ML} \pm 1 \mathrm{~mm}$ from bregna. The EBLs were made bilaterally by passing a direct current of $2.0 \mathrm{~mA}$ through a stainless steel electrode $(0.7 \mathrm{~mm}$ diameter $)$ that was insulated with Epoxylite except for $0.5 \mathrm{~mm}$ at the tip. Current was passed for $10 \mathrm{~s}$ for both the MPOA and VP. For sham lesions, the electrode was lowered to the same coordinates bilaterally, but no current was passed through the electrode.

\subsection{Histology}

After each experiment, lesioned brain regions were verified using DAPI immunostaining with the presence of spontaneous fluorescence and no nuclei were detected with DAPI staining. In the sham-control brains, fluorescence was not observed and DAPI staining revealed nuclei. Data obtained from mice with unsuccessful EBL surgeries were not included in the analysis ( $\mathrm{mPOA}=5 / 20$ surgeries, $\mathrm{VP}=5 / 15$ surgeries). Data from five sham-operated mice in the mPOA and VP regions were used.

\subsection{Behavioral tests}

Sires and dams were separated from their pups simultaneously and placed in a clean cage containing fresh wood chips for $10 \mathrm{~min}$. They were then returned to their home cage with five selected pups placed at the opposite side of the nest arena, as illustrated by the schematic in Fig. 1 of Liu et al. [14]. As an index of parental behavior, two experts observed the retrieval behavior (the percentage of sires that exhibited retrieval) for $10 \mathrm{~min}$ after the reunion of the parent with his/her own pups. We designated retrieval to be positive if all five pups were retrieved within 10 min $[14,15,19]$.

Surgical lesion of the MPOA and VP regions resulted in no apparent locomotor abnormality, but these lesions did result in the abrogation of pup-directed care. The lesioned sires in some family units attack their pups: $30 \%$ of the mPOA-lesioned and $20 \%$ of 
A Retrieval

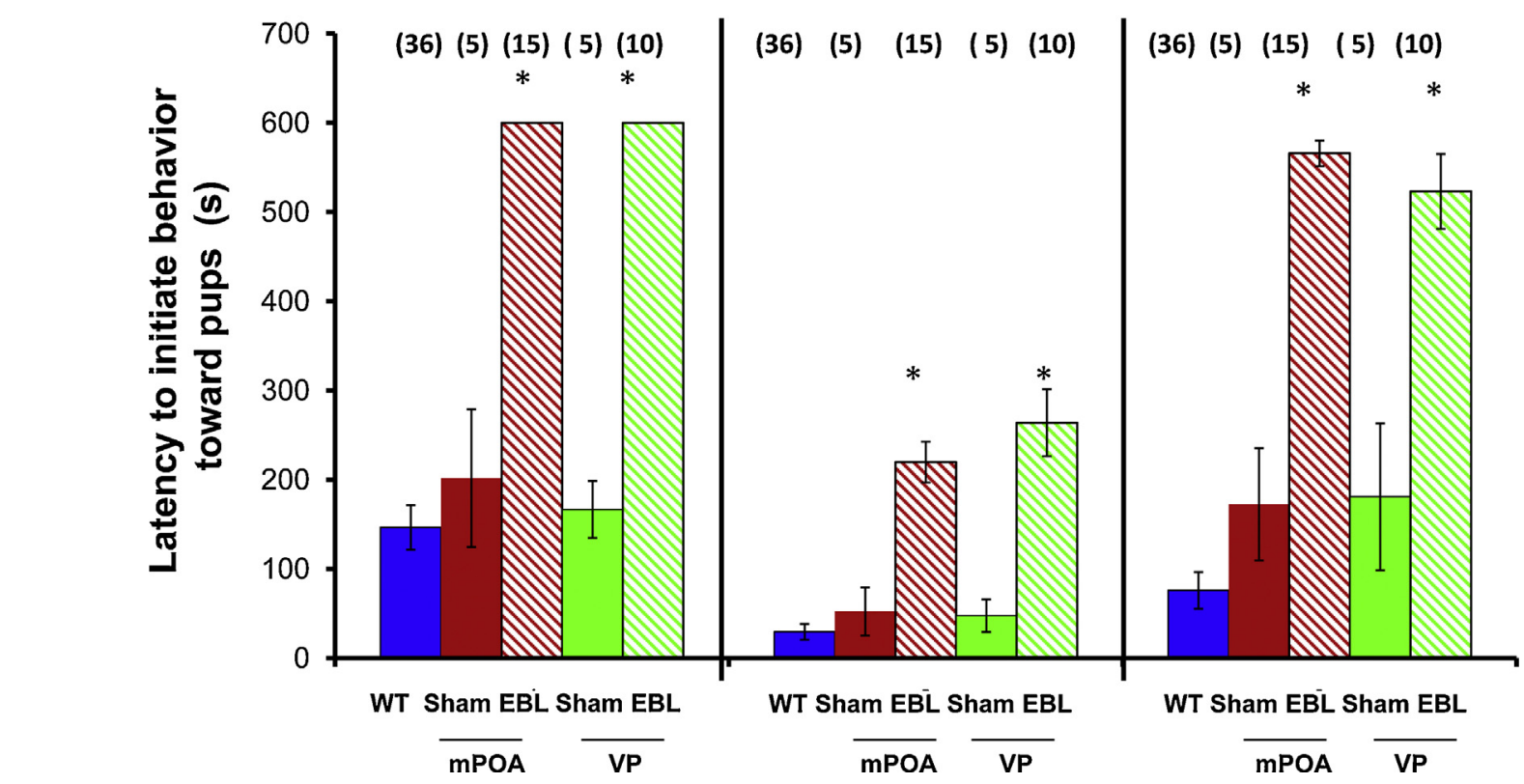

B Grooming

(36) (5) (15) (5) (10)
C Crouching

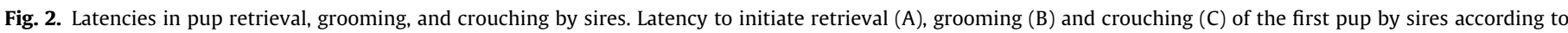

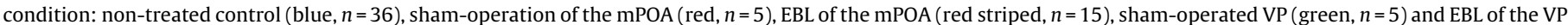

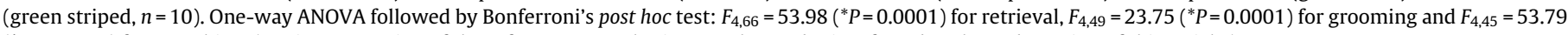
$\left({ }^{*} \mathrm{P}=0.0001\right)$ for crouching. (For interpretation of the references to color in text, the reader is referred to the web version of this article.)

the VP-lesioned sires. However, when the family was composed of lesioned sires and healthy dams, the pups could survive, and we could perform pup care experiments. In contrast, in all sire plus dam lesioned families in the MPOA and VP $(n=5$, each), their biological pups were lost by no lactation and/or infanticide, though it was unclear whether the dam or sire was the killer. Thus, subsequently, we examined parental behavior using foster pups in the sire plus dam lesioned families. No infanticide was observed in 10 sham-operated sires.

The behaviors were recorded using a digital camera, and the videos were later replayed and analyzed by at least two investigators. Grooming behavior was defined as anogenital licking and body (general) licking. Crouching behavior was defined as the mouse adopting a nursing posture over the pups to provide warmth [21].

\subsection{Statistical analysis}

The data were calculated as the means and S.E.M. Twotailed Student's $t$-tests were used for single comparisons of retrieval behaviors between the sham-control and EBL groups. The remaining data were analyzed using a One-way ANOVA followed by Bonferroni's post hoc test.

\section{Results}

Fig. 1 depicts representative tissue damage with acceptable bilateral EBLs of the MPOA (Fig. 1A) or VP (Fig. 1B) regions. Bilateral $\mathrm{MPOA}$ lesions were mostly located in the anterior, lateral and medial parts of the MPOA. Bilateral VP lesions were located in the anterior, medial and posterior parts of the VP.

The sires with the bilateral EBL of the mPOA $(n=10)$ or VP $(n=5)$ did not display the mate-dependent retrieval behavior upon reunion with pups after separation (Table 1 , the second and fifth rows, $P=0.0002$ and $P=0.0039$, respectively, two-tailed Student's $t$-test), and sham-operated sires retrieved pups ( $n=$ five each for the mPOA and VP lesions) under identical condition (Table 1, the first and fourth rows). In the pairs of both sires and dams with EBL of the mPOA or VP, the sires with EBL did not retrieve pups (Table 1, third and sixth row, $P=0.0112, P=0.0039$, respectively).

The offspring born between sires with EBL of the MPOA $(n=10)$ or $\mathrm{VP}(n=5)$ and non-lesioned dams were adequately nursed by the control dams. Therefore, the pups survived into adulthood. However, pups born from dams with EBL of the mPOA $(n=5)$ or VP $(n=5)$ displayed pale skin color with no milk band on their stomach region, and died within one to three days of birth due to no lactation and/or infanticide.

Parental behaviors were commonly observed, in which pups were returned to the nest arena (retrieval, Fig. 2A) or were cared for in the nest (grooming, Fig. 2B; crouching, Fig. 2C), among the control and sham-operated sires, but this behavior was not detected among the lesioned sires. The average latency to retrieve the first pup was $600 \mathrm{~s}$ by the sires subjected to EBL of the mPOA $(n=15)$ and $600 \mathrm{~s}(n=10)$ by the sires subjected to EBL of the VP (Fig. 2A), which were significantly longer than those of the nontreated control (146.4 $\pm 25.4 \mathrm{~s}, n=36)$ and sham-operated control

Table 1

Retrieval behavior in sires with or without EBL in the mPOA or VP region coupled with dams with or without EBL.

\begin{tabular}{|c|c|c|c|c|}
\hline \multirow[t]{2}{*}{ Sire } & \multirow[t]{2}{*}{ Dam } & \multicolumn{3}{|c|}{$\begin{array}{l}\text { Percentage of sire's exhibiting } \\
\text { retrieval behavior }(N)\end{array}$} \\
\hline & & & $P(1)$ & $P(2)$ \\
\hline Sham at $\mathrm{mPOA}$ & None & $60(5)$ & & \\
\hline EBL at mPOA & None & $0(10)$ & 0.0002 & \\
\hline EBL at $\mathrm{mPOA}$ & EBL at $\mathrm{mPOA}$ & $0(5)$ & 0.0112 & \\
\hline Sham at VP & None & $80(5)$ & & \\
\hline EBL at VP & None & $0(5)$ & & 0.0039 \\
\hline EBL at VP & EBL at VP & $0(5)$ & & 0.0039 \\
\hline
\end{tabular}

$P$-values represent statistical significance from two-tailed Student's $t$-test for sires with EBL in the MPOA $(P 1)$ and the VP $(P 2)$ : comparisons between the first and fourth rows (the Sham/None pair) and second and fifth rows (the EBL/None pair); comparisons between the first and fourth rows (the Sham/None pair) and third and sixth rows (the EBL/EBL pair). 

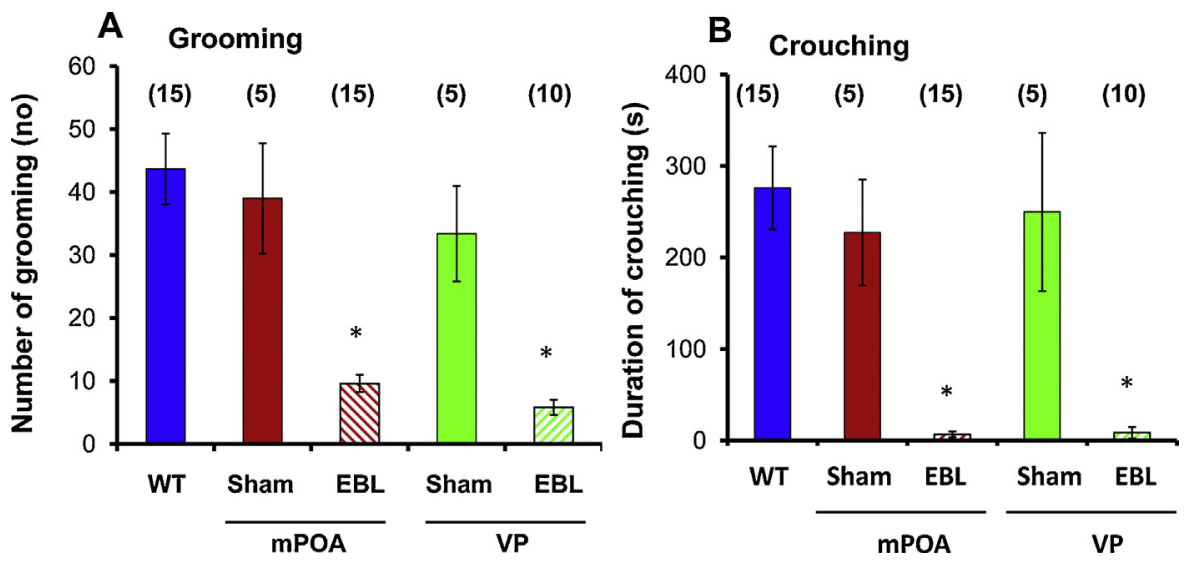

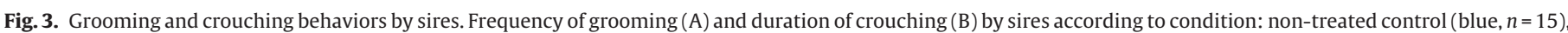

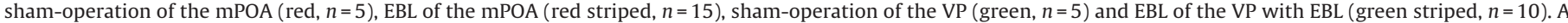

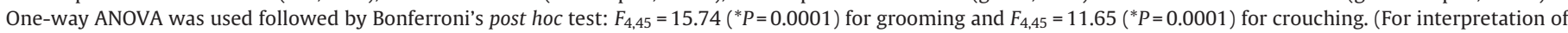
the references to color in text, the reader is referred to the web version of this article.)

sires $(201.6 \pm 86.3 \mathrm{~s}$ for the $\mathrm{mPOA}, n=5$, and $166.7 \pm 67.5 \mathrm{~s}$ for the VP, $n=5$ ) (One-way ANOVA followed by Bonferroni's post hoc analysis, $\left.F_{4,66}=53.98, P=0.0001\right)$. None of the lesioned sires returned offspring to the nest. Instead, the pups were left at various sites not just during the 10-min observation period, but for the entire day. Grooming and crouching of the pups were infrequently observed among the lesioned sires at various scattered sites.

Grooming behavior was impaired in sires with EBL of both regions. The number of grooming episodes was $43.7 \pm 5.8$ during $10 \mathrm{~min}$ in 15 non-treated control sires and $39.0 \pm 9.8$ for the shamoperated control sires in the mPOA $(n=5)$ and $33.4 \pm 8.5$ for the sham operated control sires in the VP $(n=5)$. Whereas $9.6 \pm 1.4$ grooming episodes were observed in 15 sires with EBL of the MPOA and $5.8 \pm 1.3$ episodes in 10 sires with EBL of the VP, (Fig. 3A). The number of grooming episodes was significantly lower in the sires with $\operatorname{EBL}\left(F_{4,45}=15.75, P=0.0001\right)$ and the latency to initiate pup grooming was prolonged in sires with EBL (Fig. $2 B)\left(F_{4,49}=23.75\right.$, $P=0.0001$ )

Another parental behavior, crouching, was observed in control sires. However, duration of crouching in sires with EBL was significantly shorter than that of non-treated and sham-operated control sires (Fig. 3B; One-way ANOVA followed by Bonferroni's post hoc test, $\left.F_{4,45}=11.65, P=0.0001\right)$. Latency to initiate crouching in sires with EBL was significantly prolonged (One-way ANOVA followed by Bonferroni's post hoc test, $F_{4,45}=53.79, P=0.0001$ ) than control sires (Fig. 2C).

\section{Discussion}

The present results indicate that the $\mathrm{MPOA}$ and VP regions are important for paternal retrieval behavior in mouse strains that exhibit mate-dependent paternal behavior [14]. In this study, we also demonstrated that the sires subjected to EBL of the MPOA or the VP exhibit severe deficits in other components of parental behavior, including grooming and crouching. We also found that dams subjected to EBL of the MPOA or the VPalso exhibit deficits in nurturing behavior. The lesioned sires were placed alone in new cages without any communicative interaction for $10 \mathrm{~min}$ and later returned to the home cage to observe their paternal behavior. As expected, none of the sires performed pup retrieval ( $n=10$ for each lesioned region).

The effect of mPOA lesions on maternal and paternal behavior has been studied extensively in rats and California mice [17,22-24].
Lesions of the mPOA, even quite small, block both hormonally dependent and non-hormonally mediated (pup-stimulated) displays of parental behavior in female and male rats [17,22,23,25] and California mice [26,27]. Recently, the essential role of the mPOA subregion for maternal behavior has been investigated in C57BL/6J female mice $[18,28]$. They report that the central mPOA is the indispensable subregion for mouse maternal behavior and that GABAergic and/or OT neurons in this area are transcriptionally activated during maternal behavior. Unfortunately, we were not able to examine such subregion-specific deficits, but judging from the spread of the damaged area (Fig. 1), it is possible that we lesioned areas including the central mPOA. Although we did not examine the contribution of specific neurotransmitters in modulating paternal behavior regulated by the $\mathrm{MPOA}$, this is the first report demonstrating the role of this region in mate-dependent paternal behavior using this unique paradigm.

It has been shown that the VP, located in the basal forebrain, is a major output structure of the basal ganglia [29], and it receives projections from the ventral striatal circuit. The VP is known to be an important interface between the NAcc and the motor system via the mediodorsal thalamus [29]. The MPOA acts to facilitate the active components of maternal behavior by dampening GABAergic inhibitory signals that project from the NAcc to the VP. Such disinhibition of the VP may allow pup stimuli to trigger appropriate maternal responses, especially motor responses such as retrieval, grooming and crouching [18]. Excitotoxic amino acid lesions of VP or muscimol injections into VP have also been shown to disrupt maternal behavior, with the primary behavioral effect on retrieval $[22,30]$. Our data support these finding by clearly demonstrating that sires with EBL in the VP display no paternal behaviors.

In conclusion, our current results are consistent with previously published data demonstrating the modulatory roles of the MPOA and VP on parental behavior in rodents $[6,17,22,30]$. The current and previously published findings suggest that the neural circuitry mediating paternal behavior includes the mPOA, VP and NAcc [16], may be similar to those that mediate maternal behavior as proposed by Numan and his colleagues [18].

\section{Acknowledgment}

This work was supported in part by the Strategic Research Program for Brain Sciences from the Ministry of Education, Culture, Sports, Science, and Technology, Japan. 


\section{References}

[1] E.F. Duque, C.R. Valeggia, S.P. Mendoza, The biology of paternal care in human and nonhuman primates, Annu. Rev. Anthropol. 38 (2009) 115-130.

[2] A.C. Kentner, A. Abizaid, C. Bielajew, Modeling dad: animal models of paternal behaviour, Neurosci. Biobehav. Rev. 34 (2010) 438-451.

[3] T.R. de Jong, M. Chauke, B.N. Harris, W. Saltzman, From here to paternity: neural correlates of the onset of paternal behavior in California mice (Peromyscus californicus), Horm. Behav. 56 (2009) 220-231.

[4] B. Leuner, E.R. Glasper, E. Gould, Parenting and plasticity, Trends Neurosci. 33 (2010) 465-473

[5] R. Bridges, Parenting and the brain: an overview, in: R.S. Bridges (Ed.), Neurobiology of the Parental Brain, Academic Press, Elsevier, MA, 2008

[6] K.O. Kuroda, K. Tachikawa, S. Yoshida, Y. Tsuneoka, M. Numan, Neuromolecular basis of parental behavior in laboratory mice and rats: with special emphasis on technical issues of using mouse genetics, Prog. Neuropsychopharmacol. 35 (2011) 1205-1231.

[7] L.A. McGraw, L.J. Young, The prairie vole: an emerging model organism for understanding the social brain, Trends Neurosci. 33 (2010) 103-109.

[8] K.E. Wynne-Edwards, M.E. Timonin, Paternal care in rodents: weakening support for hormonal regulation of the transition to behavioral fatherhood in rodent animal models of biparental care, Horm. Behav. 52 (2007) 114-121.

[9] T.R. Insel, The challenge of translation in social neuroscience: a review of oxytocin, vasopressin, and affiliative behavior, Neuron 65 (2010) 768-779.

[10] C.S. Carter, E.M. Boone, H. Pournajafi-Nazarloo, K.L. Bales, Consequences of early experiences and exposure to oxytocin and vasopressin are sexually dimorphic, Dev. Neurosci. 31 (2009) 332-341.

[11] M.E. Modi, L.J. Young, The oxytocin system in drug discovery for autism: animal models and novel therapeutic strategies, Horm. Behav. 61 (3) (2012) 340-350.

[12] H. Yamasue, J.R. Yee, R. Hurlemann, J.K. Rilling, F.S. Chen, A. Meyer-Lindenberg, $\mathrm{H}$. Tost, Integrative approaches utilizing oxytocin to enhance prosocial behavior: from animal and human social behavior to autistic social dysfunction, J. Neurosci. 32 (2012) 14109-14117.

[13] J.S. Rosenblatt, Nonhormonal basis of maternal behavior in the rat, Science 156 (1967) 1512-1514.

[14] H.X. Liu, O. Lopatina, C. Higashida, H. Fujimoto, S. Akther, A. Inzhutova, M. Liang, J. Zhong, T. Tsuji, T. Yoshihara, K. Sumi, M. Ishiyama, W.J. Ma, M. Ozaki, S. Yagitani, S. Yokoyama, N. Mukaida, T. Sakurai, O. Hori, K. Yoshioka, A. Hirao, Y. Kato, K. Ishihara, I. Kato, H. Okamoto, S.M. Cherepanov, A.B. Salmina, H. Hirai, M. Asano, D.A. Brown, I. Nagano, H. Higashida, Displays of paternal mouse pup retrieval following communicative interaction with maternal mates, Nat. Commun. 4 (2013) 1346.

[15] H. Fujimoto, H.X. Liu, O. Lopatina, D.A. Brown, H. Higashida, Scopolamine modulates parental retrieval behavior in mice induced by the maternal mate, Neurosci. Lett. 546 (2013) 63-66.

[16] S. Akther, N. Korshnova, J. Zhong, M. Liang, S.M. Cherepanov, O. Lopatina, Y.K. Komleva, A.B. Salmina, T. Nishimura, A.K.M.F. Azam, H. Hirai, I. Kato, Y.
Yamamoto, S. Takasawa, H. Okamoto, H. Higashida, CD38 in the nucleus accumbens and oxytocin are related to paternal behavior in mice, Mol. Brain 6 (2013) 41.

[17] M. Numan, J.S. Rosenblatt, B.R. Komisaruk, Medial preoptic area and onset of maternal behaviour in the rat, J. Comp. Physiol. Psychol. 91 (1977) $146-164$.

[18] M. Numan, D.S. Stolzenberg, Medial preoptic area interactions with dopamine neural systems in the control of the onset and maintenance of maternal behavior in rats, Front. Neuroendocrinol. 30 (2009) 46-64.

[19] D. Jin, H.X. Liu, H. Hirai, T. Torashima, T. Nagai, O. Lopatina, N.A. Shnayder, K. Yamada, M. Noda, T. Seike, K. Fujita, S. Takasawa, S. Yokoyama, K. Koizumi, Y. Shiraishi, S. Tanaka, M. Hashii, T. Yoshihara, K. Higashida, M.S. Islam, N. Yamada, K. Hayashi, N. Noguchi, I. Kato, H. Okamoto, A. Matsushima, A. Salmina, T. Munesue, N. Shimizu, S. Mochida, M. Asano, H. Higashida, CD38 is critical for social behaviour by regulating oxytocin secretion, Nature 446 (2007) 41-45.

[20] B.J. Keith, Franklin, G. Paxinos, The Mouse Brain in Stereotaxic Coordinates, Compact, 3rd ed., Academic Press, New York, 2008.

[21] J.S. Lonstein, G.J. de Vries, Sex differences in the parental behavior of rodents, Neurosci. Biobehav. Rev. 24 (2000) 669-686.

[22] M. Numan, K.P. Corodimas, M.J. Numan, M.J.E.M. Factor, W.D. Piers, Axonsparing lesions of the preoptic region and substantia innominata disrupt maternal behavior in rats, Behav. Neurosci. 102 (1988) 381-396.

[23] J.S. Rosenblatt, S. Hazelwood, J. Poole, Maternal behavior in male rats: effects of medial preoptic area lesions and presence of maternal aggression, Horm. Behav. 30 (1996) 201-215.

[24] J.D. Sturgis, R.S. Bridges, N-methyl-DL-aspartic acid lesions of the medial preoptic area disrupt ongoing parental behavior in male rats, Physiol. Behav. 62 (1997) 305-310.

[25] M. Kalinichev, J.S. Rosenblatt, J.I. Morrell, The medial preoptic area, necessary for adult maternal behavior in rats, is only partially established as a component of the neural circuit that supports maternal behavior in juvenile rats, Behav. Neurosci. 114 (2000) 196-210.

[26] A.W. Lee, R.E. Brown, Comparison of medial preoptic, amygdala, and nucleus accumbens lesions on parental behavior in California mice (Peromyscus californicus), Physiol. Behav. 92 (2007) 617-628.

[27] J.S. Lonstein, Effects of dopamine receptor antagonism with haloperidol on nurturing behavior in the biparental prairie vole, Pharmacol. Biochem. Behav. 74 (2002) 11-19.

[28] Y. Tsuneoka, T. Maruyama, S. Yoshida, K. Nishimori, T. Kato, M. Numan, K.O. Kuroda, Functional, anatomical, and neurochemical differentiation of medial preoptic area subregions in relation to maternal behavior in the mouse, J. Comp. Neurol. 521 (2013) 1633-1663.

[29] L. Heimer, R.D. Switzer, G.W. Vanhoesen, Ventral striatum and ventral pallidum - components of the motor system, Trends Neurosci. 5 (1982) 83-87.

[30] M. Numan, M.J. Numan, J.M. Schwarz, C.M. Neuner, T.F. Flood, C.D. Smith, Media preoptic area interactions with the nucleus accumbens-ventral pallidum circuit and maternal behavior in rats, Behav. Brain Res. 158 (2005) 53-68. 